\title{
BMJ Open Exploring sustainable primary care responses to intimate partner violence in New Zealand: Qualitative use of complexity theory
}

\author{
Claire Gear (D) , ${ }^{1}$ Jane Koziol-Mclain (D) , ${ }^{1}$ Elizabeth Eppel (D) ${ }^{2}$
}

To cite: Gear C, Koziol-Mclain J, Eppel E. Exploring sustainable primary care responses to intimate partner violence in New Zealand: Qualitative use of complexity theory. BMJ Open 2019;9:e031827. doi:10.1136/ bmjopen-2019-031827

- Prepublication history and additional material for this paper are available online. To view these files, please visit the journal online (http://dx.doi. org/10.1136/bmjopen-2019031827).

Received 21 May 2019 Revised 10 September 2019 Accepted 02 October 2019

Check for updates

(c) Author(s) (or their employer(s)) 2019. Re-use permitted under CC BY-NC. No commercial re-use. See rights and permissions. Published by BMJ.

${ }^{1}$ Centre for Interdisciplinary Trauma Research, Auckland University of Technology Faculty of Health and Environmental Sciences, Auckland, New Zealand

${ }^{2}$ School of Government, Victoria University of Wellington, Wellington, New Zealand

Correspondence to

Dr Claire Gear;

claire.gear@aut.ac.nz

\section{ABSTRACT}

Objective To explore what affects sustainable responses to intimate partner violence within New Zealand primary care settings using complexity theory.

Design Primary care professional interviews on intimate partner violence as a health issue are analysed using a complexity theory-led qualitative research methodology grounded in poststructuralism.

Setting Four general practices in one region of the North Island of New Zealand, two serving a general patient population and two adopting an indigenous approach. Participants Seventeen primary care professionals and management from the four recruited general practices. Results The complex adaptive system approach the 'Triple R Pathway', calls attention to system interactions influencing intimate partner violence responsiveness across health system levels. Four exemplars demonstrate the use of the Triple R Pathway. Two key system areas challenge the emergence of primary care responsiveness: (1) Non-recognition of intimate partner violence as a key determinant of ill-health. (2) Uncertainty and doubt. Conclusions The relationship between intimate partner violence and ill-health is not well recognised, or understood in New Zealand, at both policy and practice levels. Inadequate recognition of socioecological determinants of intimate partner violence leads to a simple health system response which constrains primary care professional responsiveness. Constant intervention in system interactions is needed to promote the emergence of sustainable responses to intimate partner violence.

\section{INTRODUCTION}

Intimate partner violence (IPV) is a global public health problem of epidemic proportions. ${ }^{1}$ It is known as a complex problem, recognising the myriad of entangled factors which contribute to, and sustain, violence in people's lives. ${ }^{2}$ However, despite a considerable body of research, integrating effective and sustainable responses to IPV has proven challenging internationally. The best evidence-based practice is still unknown and little progress has been made on the front line. ${ }^{1}$ Often unknowingly, health professionals may treat the sequela of violence without addressing the cause. ${ }^{1}$ Known
Strengths and limitations of this study

This study demonstrates innovative use of complexity theory as a qualitative research methodology.

- We reconceptualise health systems as complex adaptive systems, calling attention to contextual factors and patterns of interaction which influence intervention implementation and sustainability.

- The largest weakness of this study is absence of care-seeker and community voices and their influence on sustainable healthcare responses to intimate partner violence.

as a setting likely to encounter persons with signs and symptoms of violence, primary care is internationally recognised as a priority setting for service delivery. ${ }^{3}$ Yet, clinicians often do not recognise the signs and symptoms of violence and lack confidence in asking. ${ }^{4-6}$ World Health Organisation guidelines recommend that at a minimum, health professionals should be able to provide a first-line response involving facilitating disclosure, offering support and referral, providing medical treatment and follow-up care, and documenting evidence. ${ }^{3}$

New Zealand healthcare is largely funded through general taxation. Health policy is directed by the Ministry of Health (MOH) through District Health Boards (DHBs) which fund and provide health services for their regional population. Primary healthcare is provided via DHB service agreements with regional Primary Health Organisations (PHOs) who contract service providers to deliver care, largely general practices. General practices connect with other community services such as Plunket (child well-being) or midwifery to ensure a continuum of care. Idiosyncratically, general practices are mostly private businesses largely autonomous to public governance. ${ }^{78}$ Significant and enduring health inequities exist between New Zealand indigenous Māori (the indigenous people of New Zealand) and 
non-Māori, despite the protections of Te Tiriti o Waitangi (The Treaty of Waitangi, the founding document of New Zealand). ${ }^{9}$ Lifetime rates of IPV are significantly higher for Māori women (one in two) than for non-Māori women (one in three).$^{10}$ Increasingly, kaupapa Māori practices which reclaim Te Ao Māori (the Māori World) principles are being recognised as effective means to address violence within whānau (extended family), though these practices are often stymied by racist health systems and services. ${ }^{9}{ }^{11}$ The reader should note IPV is understood as a pattern of cumulative harm encompassing multiple victims (adults and children), past, current and future. The term family violence is used to recognise the extended nature of harms. ${ }^{12}$

The New Zealand health system response to family violence largely lies within the $\mathrm{MOH}$ Violence Intervention Programme, responsible for identifying, assessing and referring those experiencing IPV or child abuse and neglect. Premised on a standardised comprehensive systems approach ${ }^{13}$ the programme established infrastructure components (such as intervention guidelines and training) to support health professional responses in hospital and selected community settings. However, service consistency and quality remain suboptimal. Engagement with the primary care sector has been limited. ${ }^{14-16}$ Two decades ago, Elvidge $^{5}$ found general practitioners (GPs; primary care doctors) were concerned they were working ineffectively by missing cases of IPV or intervening poorly. Still today, there is limited policy, funding or resources to support the primary care sector to respond to IPV, a profound system gap. $^{14}$

Using complexity theory, we sought to understand what affects a sustainable response to IPV within New Zealand primary care settings. From this theoretical lens, sustainability may be viewed as an emergent phenomenon, generated by interactions between elements within a complex adaptive system. For example, when interaction between the care-seeker and primary care generate mutual benefits, such as reduced violence and health professional confidence. In this context, sustainability cannot be achieved in perpetuity but must be constantly worked toward. ${ }^{17}$ Primary prevention strategies become an intrinsic part of every interaction regarding IPV. ${ }^{12}$ This paper presents the 'Triple R Pathway' which emerged from exploring primary care professional discourses on responding to IPV as a health issue. We provide four exemplars of how the Triple $\mathrm{R}$ Pathway calls attention to system interactions influencing responsiveness to IPV. Two key system areas which challenge primary care responses to IPV are discussed alongside ways to promote the emergence of sustainability.

\section{METHODS}

Complexity theory has been usefully applied to study systems involved in the New Zealand response to family violence. ${ }^{12}$ Complexity theory reconceptualises healthcare systems as complex adaptive systems, focusing on how interactions between system elements co-evolve and self-organise into new behaviours. Over time, these behaviours may lead to new system structures. ${ }^{18}$ Complex adaptive systems are inherently unpredictable due to the diversity and non-linearity of system interactions. Uncertainty is generated by the complexity of the problem, the contingent reactions of individual agents in response to unknowns, and a lack of codified knowledge. Begun and Kaissi ${ }^{19}$ define uncertainty as 'the inability of agents in systems to accurately predict the consequences of an action or the future state of the agent, the system, or the environment' (p.110). Within complex adaptive systems, small changes may lead to big effects and vice versa. ${ }^{20}$

In this study, we applied complexity theory as a qualitative research methodology. ${ }^{21}$ Consistent with the focus on interaction, we chose to position our methodological approach within the poststructural paradigm that focuses on how knowledge is constructed through interaction between concept and language. For example, a view of IPV as a health issue represents particular views about our health and how healthcare should be practised. ${ }^{22} 23$ Limited literature exists on applying complexity theory as a qualitative methodology. We conducted interviews with 17 primary care professionals on IPV as a health issue. A complexity-led discourse analysis was developed which focused on identifying the function of participant narratives. $^{21} 24$

\section{Patient and public involvement}

Three public members were involved in the study as advisors, from research design to conclusions. Dr Clare Healy, a practising GP and specialist in family and sexual violence, provided guidance on issues for primary care professionals related to family violence. Dr Anna Rolleston, a senior Māori health researcher, provided guidance on study conduct, ethics and responsiveness to Māori. Tamati Tata, a kaumātua (an elder of status), provided guidance on cultural responsiveness. All advisors provided feedback on this manuscript and will support dissemination of findings. Patients were not involved in the design, analysis or interpretation of this research study.

\section{Setting and recruitment}

This study was conducted within a region of the North Island of New Zealand. We sought to recruit four general practices; two serving a general patient population and, in recognition of the New Zealand Tiriti o Waitangi, two adopting a kaupapa Māori approach for the indigenous Māori population. Collecting multiple health professional data within four settings allowed access to the different macrodiversities and microdiversities represented in the complex system of primary care. The primary researcher (CG) worked to build relationships in the field to recruit participants using snowball sampling. Across the four practices, all primary care professionals interested in participating were recruited. Seventeen of 43 practices in the region were initially approached to recruit the four practices. Practices declined to participate due to 
capacity restrictions, absence of interest, not recognising IPV as an issue for patients or claiming no knowledge to contribute. Others were already participating in other research studies, undergoing organisational restructure or did not provide a reason. Practices agreed to participate due to interest in the issue and researcher-developed relationships.

Across the four recruited general practices, 19 health professionals were invited to participate in a $30 \mathrm{~min}$ interview on IPV as a health issue, including 4 practice managers, and 2 managers representing associated PHOs. Two participants declined to participate, one due to lack of interest and the other provided no reason. Among the 17 participants recruited there were 3 men and 14 women. Roles included four practice managers, two PHO managers, four GPs, four practice nurses, one nurse practitioner, one administrator and one social worker. An agreement with the four participating general practices and 17 health professionals specified confidentiality, preventing detailed reporting of participant characteristics, such as age and ethnicity.

Informed consent was obtained in writing from the practice manager at each general practice and health professional informed consent recorded verbally. Participants were offered a $\$ 50$ supermarket voucher to compensate for any costs incurred by participating. As the interview would address a sensitive topic, both personally and professionally, we anticipated some participant discomfort. To offset this, we chose not to ask participants directly about encounters with IPV, rather focusing on how IPV is conceptualised as a health issue. This aimed to give participants discretion on what they chose to share, though many volunteered IPV experiences as a health professional. Help-seeking advice was included in the participant information sheet.

\section{Data collection}

Interviews, conducted by a skilled researcher, were audiorecorded. Interviews ranged from $30 \mathrm{~min}$ to $70 \mathrm{~min}$ and were conducted in private at locations convenient to the participant, mostly the workplace. An interview guide was developed, designed to identify and explore discourses influencing responses to IPV. This was revised after five interviews to address a concern data tended towards health system complexity, rather than the complexity of responding to IPV. The revised guide was unstructured and conversational, to better elicit response diversity and complexities.

\section{Data analysis}

Primary analysis was conducted by the interviewer with discussion among all authors. Interviews were transcribed and audited using Dragon ${ }^{25}$ and uploaded to NVivo. ${ }^{26}$ Analysis occurred in three phases, responsive to what emerged from the data. First, interviews were coded for broad areas of 'talk'. Code names and descriptions used participant words to offset data reduction. A second coding round checked for misunderstanding and validity.
Two hundred narrative strings reflecting organisational discourses were found, consistent with the research aim of maintaining diversity.

Second, narrative analysis was applied to explore deeper into each of the codes. Individual narratives were developed to preserve the diversity and context of each individual. Narratives were analysed for 'small stories' to capture the diverse ways the narratives were constructed and shaped by different contexts. ${ }^{27}$ The small stories were analysed for their function-what message(s) did the participant intend to convey-supported by narrative analysis questions derived from De Fina and Georgakopoulou. ${ }^{27}$ For each participant a key narrative, or dominant discourse emerged from the analysis.

Third, we viewed each participant narrative as a complex adaptive system using the concepts of interaction, co-evolution, self-organisation and emergence. This involved exploring what the health professional thought and how that was a product of their interaction with their own contexts. This led to an understanding of why they conveyed what they did, the function of the narrative. In complexity terms, we explored how patterns of interaction between participant and environment were selforganising into a dominant discourse that influenced practice. A pattern emerged where who the participant was shaped how they conceptualised an IPV response which, in turn, influenced how responsive they could be to IPV. We named this pattern the 'Triple R Pathway' and successfully tested the pattern on the 17 participant narratives by developing complexity-led narratives mapping individual Triple R Pathways. In the following section we describe the Triple R Pathway before demonstrating its use with a selected participant exemplar from each general practice. The reader is encouraged to access the online supplementary material which maps participant Triple R Pathways not included here.

\section{Findings: the Triple $\mathbf{R}$ pathway}

Analysis exposed multiple meanings of an IPV response where individual and organisational discourses are competing for dominance. Emergent from analysis, the Triple R Pathway is a complex adaptive system approach that calls attention to system interactions influencing responsiveness to IPV in primary care across clinician, general practice and health system levels (see figure 1). It demonstrates how health professionals and healthcare organisations self-organise to be responsive, or unresponsive to patients impacted by IPV.

How a health professional may respond to IPV is influenced by the individual's worldview, philosophy or model of care. This sets a path-dependency (how history influences current behaviour and events) for how a professional may interact with a person impacted by IPV. ${ }^{21}$ For example, a health professional who views IPV as a problem for a particular social or ethnic group may be less responsive than a patient-centred practitioner who views each patient as different. The individual's respond 


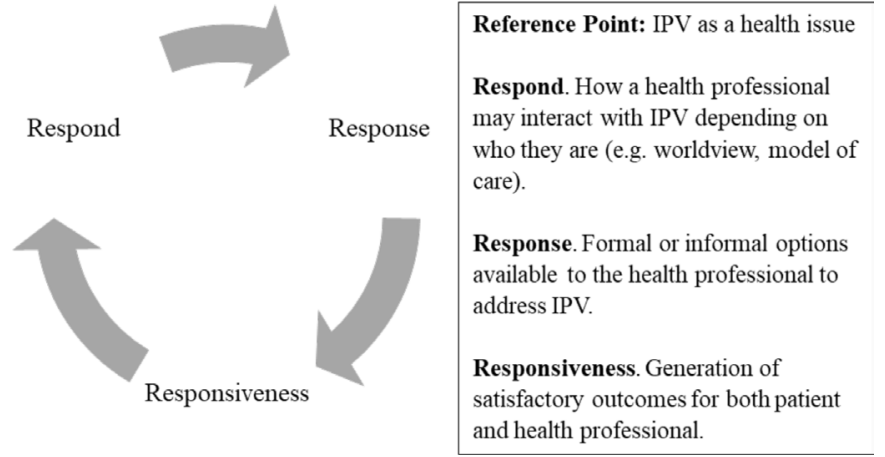

Figure 1 The Triple R pathway.

stance shapes what formal or informal response a health professional may conceptualise, including doing nothing.

A response discourse is generated in relationship to an individual's understanding of IPV as a health issue (interview reference point). That is, how they understand IPV as a health issue influences how they think of a response. For example, if IPV is unrecognised as a health issue, a response discourse and responsiveness become non-existent. Competing discourses may view the reference point differently, influencing response discourses.

How responsive a health professional may be is the selforganisation of multiple, diverse and non-linear system interactions along this path, including interactions with those living with violence. Patterns of interaction between each part of the pathway, respond, response, responsiveness, self-organise to generate responsiveness. For example, an unexpected disclosure may prompt the health professional to seek better response resources, improving their responsiveness and altering their respond stance. Alternatively, an encounter which leads to further harm may alter the respond stance (less confidence) restricting the response discourse (do not engage), leading to reduced responsiveness. Each part of the pathway is dynamic, constantly interacting with and within each other.

Figure 2 depicts the Triple R Pathway across clinician, general practice and health system levels. Viewed horizontally, the figure shows how interactions between levels co-evolve. Viewed vertically, the figure shows how system interactions within each level co-evolve, leading to selforganised responsiveness. Sustainable responses to IPV will emerge when these patterns of interaction repeat to form a positive feedback loop at each level.
To demonstrate the use of the Triple R Pathway we provide a participant exemplar from each general practice. Each section begins by briefly describing interactions occurring within the general practice before exploring the exemplar. Participant respond stances and response discourses are summarised in table 1 , and their influence on responsiveness is discussed below. Pseudonyms replace participant and organisation names.

\section{Whānau Oranga}

Whānau Oranga (family health) provides accessible lowcost services to whānau using a kaupapa Māori approach. We interviewed seven Whānau Oranga workers: the practice manager, GP, nurse practitioner, practice nurse, administrator, social worker and the associated PHO manager. Across participants, we found the dominant respond stance was about providing for the needs of the people. This generated a diversity of response discourses and wide-ranging ways of being responsive.

Participants were connected by an environment of complex patient health and social needs and relied on connectivity with community services (eg, mental health services, financial support) to provide effective care. All seven participants described different ways health system structure prevented the practice from transforming into a more effective model of care. At the time of data collection, community services had variable influence on IPV responsiveness. The inability to transform to another model of care more effective for their patients, such as Whānau Ora (an indigenous health initiative driven by Māori cultural values), meant Whānau Oranga struggled to fulfil their respond stance of providing for the needs of the people. The following explores the Triple R Pathway of Rachel, a Nurse Practitioner at Whānau Oranga.

\section{Rachel, nurse practitioner}

Rachel's response discourse 'making sure I know what to do' is driven by a passionate respond stance of 'just wanting to make a difference'. Rachel felt challenged initially to address IPV because she was not comfortable to ask and did not know what to do about it. This was amplified when she began working at Whānau Oranga.

To come into this practice and $60 \%$ plus of our women and some of the men have been exposed [to IPV] it was a bombshell really. It was difficult to start with because a lot of it was to do with mental health and

\begin{tabular}{|c|c|c|c|c|}
\hline \multirow[b]{2}{*}{$\downarrow$} & Clinician $\rightarrow$ & $\leftarrow$ General Practice $\rightarrow$ & $\leftarrow$ Health System & \multirow{5}{*}{ 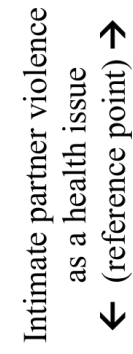 } \\
\hline & $\begin{array}{c}\text { Respond } \\
\text { (worldview, model of care) }\end{array}$ & $\begin{array}{c}\text { Respond } \\
\text { (practice philosophy) }\end{array}$ & $\begin{array}{c}\text { Respond } \\
\text { (health strategy) }\end{array}$ & \\
\hline $\begin{array}{c}\text { Co-evolution } \\
\downarrow\end{array}$ & $\begin{array}{c}\text { Response } \\
\text { (competing discourses) }\end{array}$ & $\begin{array}{c}\text { Response } \\
\text { (dominant discourse) }\end{array}$ & $\begin{array}{c}\text { Response } \\
\text { (health policy discourse) }\end{array}$ & \\
\hline $\begin{array}{l}\text { Self-organisation } \\
\downarrow\end{array}$ & $\begin{array}{c}\text { Responsiveness } \\
\text { (satisfactory outcomes) }\end{array}$ & $\begin{array}{c}\text { Responsiveness } \\
\text { (population needs) }\end{array}$ & $\begin{array}{l}\text { Responsiveness } \\
\text { (health targets) }\end{array}$ & \\
\hline Emergence & $\begin{array}{l}\text { Sustainability } \\
\text { (mutual benefit) }\end{array}$ & $\begin{array}{c}\text { Sustainability } \\
\text { (patient health/wellbeing) }\end{array}$ & $\begin{array}{c}\text { Sustainability } \\
\text { (population health) }\end{array}$ & \\
\hline
\end{tabular}

Figure 2 The Triple R pathway across system levels. 
Table 1 Four exemplar Respond stances and Response discourses

\begin{tabular}{|c|c|c|c|}
\hline General practice & Participant & Respond stance & Response discourse \\
\hline Whānau Oranga & Rachel, nurse practitioner & I just want to make a difference & Making sure I know what to do \\
\hline Family Care Practice & Anna, general practitioner & $\begin{array}{l}\text { It's a big problem unrecognised } \\
\text { for its importance }\end{array}$ & I just need to do it \\
\hline Te Whānau Hauora & Hana, practice manager & $\begin{array}{l}\text { We engage differently with } \\
\text { whānau }\end{array}$ & It just doesn't happen like that \\
\hline First Medical Care & Mike, practice manager & IPV is a human rights violation & $\begin{array}{l}\text { We need an effective and consistent } \\
\text { process }\end{array}$ \\
\hline
\end{tabular}

sexual abuse. [...] It was emotionally taxing, more than I expected.

This environment changed the way she looked at a problem and the way she practiced. Her respond stance motivated her to identify people needing help. This was reinforced when she was able to help someone, supported by access to community services, but challenged when poor communication with community services made referral difficult.

I had a guy come in on Thursday and no money, partner used the benefit money for drugs, no food, didn't know where he was going to go, was in crisis. Didn't go to the ED, came down here, crying in the corridor. I could immediately run to [location] and find out when the social worker was going to be back, I could give him a food parcel for the weekend and he knew that he could come back if he needed to. There are some general practices that that couldn't have happened then and there, and we might have just referred him through to crisis team mental health. But because we could do it here, and he trusted us as his healthcare provider, that made a difference to him immediately rather than sending him somewhere else or waiting. I mean you'd have to ask him from his perspective whether it was actually that good, but it felt good from my perspective because I could do something.

'Just wanting to make a difference' directly, and strongly, influenced Rachel's response discourse of 'making sure I know what to do'. Feeling challenged to respond effectively motivated her to educate herself, voluntarily, on how to do that. She needed to make sure she knew what to do to be able to make a difference, illustrating the strength of the relationship between her respond stance and response discourse.

Rachel's strong respond stance and response discourse positively influenced her responsiveness. Faced with a complex problem, she was motivated to take steps to ensure provision of good care, while managing the doubt involved.

Always in general practice you live with that level of discomfort, that level of uncertainty. Because sometimes you're never really sure that that's the right diagnosis, but you trust your training, your instincts and the patient's history to go down a particular course.

Rachel's personal desire to make a difference for people generates beneficial outcomes both for herself and her patients. However, these interactions are being blocked from self-organising into a positive and repeated pattern by other system interactions outside of her control. She called attention to the general practice funding model as a main constraint. She believed the practice could become more responsive, such as referring patients to community services, but the funding model blocks transformation to a model of care more responsive to the complex health and social needs of their patients.

\section{Family Care Practice}

Family Care Practice provides care to a general, mid-tohigh socioeconomic patient population. We interviewed three Family Care Practice workers: a practice manager, practice nurse and GP. Across the participants, we found the dominant respond stance was 'we can do better'. Both the practice nurse and the GP were responsive when they encountered violence and were willing to put systems and processes in place. However, known options available to address IPV were missing at Family Care Practice constraining responsiveness.

The willingness to address IPV had not reached practice management, which was largely focused on achieving top-down directives to ensure business survival. The practice manager held a competing response discourse of 'it's (responsiveness) probably happening anyway', suggesting no further action was needed. The invisibility of IPV as a health issue at the health system level supported this competing discourse, both contributing to a lack of workplace support and diminishing front-line voices. The assumption health professionals could effectively address IPV with existing skills had an effect of isolating the GP and practice nurse who felt they could be doing better. The following explores the Triple R Pathway of Anna, a GP at Family Care Practice.

\section{Anna, GP}

Anna's response discourse 'I just need to do it', derives from recognition that family violence is a big problem for 
healthcare, unrecognised for its importance, her respond stance. Anna claims family violence is not discussed enough in healthcare, believing professionals find it difficult to talk about because they have not been trained to deal with it and they may not respond well. She describes a situation which occurred when she first qualified as a doctor.

It's something I definitely felt like I wasn't welltrained for. I remember seeing a case, well it was a litthe girl [...] I remember seeing her in ED [emergency department] and she had this vaginal discharge and she was four. And I didn't feel happy screening the mother about possible abuse [...] and I felt completely out of my comfort zone. I went and asked the ED consultant to go to see her and then she was like "oh no, you do it and see how you get on". Well I just felt completely useless, I didn't think I was doing well, I didn't want to offend her, but I felt like I wasn't doing a good job and I was worried about was I doing an adequate job. I asked Paediatrics to come and see her as well and they refused, they said they didn't need to, just for us to do a swab and that was it. It came back as gonorrhoea, and she was [being abused]. Then it obviously all got dealt with and everyone was involved. I remember feeling that I just felt terrible, like I didn't really feel that I had the tools to question this lady about her 4 year-old child when clearly, and she did, as it turned out, had no idea that anything was going on, no clue.

Anna believes it is only when you see victims of violence that you realise how common it is. She advocates for increased understanding and awareness so effective support can be provided straightaway making 'such a difference to people's lives later on down the track'.

Anna's recognition of family violence as a big and important problem (respond stance) leads to her response discourse 'I just need to do it'. She rationalises health professionals are concerned about what they need to do, how much time it will involve and what referral resources are available. The known prevalence of IPV can also act as a barrier to screening, for fear of a lot of positive responses.

I think it's about having the systems in place to um, that you can refer to so you're not feeling left to deal with it on yourself and feeling completely isolated [...] sometimes you feel like you've got no support from anyone else, and you just don't have the time to spend with people. Well you can keep getting them back and even not charging them, or you know just making phone calls and all the rest of it, but you sometimes just feel so unsupported around issues, when you know it's so important to deal with it and the risks.

Anna knows she must have met people experiencing IPV without realising it. She believes it is about timing for people, asking the right questions and providing an environment where they can talk about it. An open, trusted relationship is key, but she acknowledges it may be helpful to some and not others. Anna's respond stance, 'it's a big unrecognised issue' and response discourse, 'I just need to do it', means she is responsive when she encounters violence. However, Anna feels like she could do it better. She is aware and willing to engage with IPV, but her responsiveness is not yet fully realised as it is blocked by other system interactions, such as an absence of dialogue between health professionals on addressing IPV in practice.

\section{Te Whānau Hauora}

Te Whānau Hauora (The Family Health) provides care to a largely low-to-mid socioeconomic Māori community, focusing on health promotion and regular access to a GP. We interviewed three Te Whānau Hauora workers: the practice manager, GP and associated PHO Manager. Across the participants, we found the dominant respond discourse to be 'we have to engage differently'. This generated a dominant response discourse which acknowledged a wide range of complexities involved in addressing IPV.

The relationships between the participants were very loose. The PHO manager and practice manager shared an understanding of IPV as inherently connected to socioecological determinants. The GP was reluctant to address IPV presentations and had only recently formed his narrative of IPV as a health issue. The following explores the Triple R Pathway of Hana, the practice manager of Te Whānau Hauora.

\section{Hana, practice manager}

Hana's response discourse 'it just doesn't happen like that' is influenced by a strong respond stance that her organisation engages with whānau (family) differently to other healthcare services. She argues a first-line response would be ineffectual as IPV does not present to the hauora in that way. For Hana, IPV occurs because of problems at home, such as unemployment or substance abuse. She says whānau find it difficult to, and are fearful of, asking for help. This is why she seeks to engage whānau differently, in ways which open spaces for people to ask for help for anything, including IPV.

Hana's respond stance significantly influences her response. 'So ideally, we would love them to come to us first, before it all happens, but it just doesn't happen like that.' Instead the hauora provide advocacy support for whānau members who present at hospital and host wananga (seminar discussions) to provide a space for people to ask for help. Te Whānau Hauora engages with the whole family, recognising suffering affects more than the individual. Hana's response, 'it doesn't happen like that', continually reinforces her respond stance, 'we must engage differently' and vice versa. She illustrates why engaging differently is important.

But how do you do that, how do you go to a family member: 'Oh how you been? Actually, have you been bashed lately?' You know, who the hell does that? 
That's disrespectful in the first instance. It wouldn't work here. We wouldn't do it like that because it's not part of who we are as a people. [...] Oh! Can you imagine the comebacks "Who does she think she is, coming into my home or telling me, and asking me shit like that?' You know, that's disrespectful first. [...] whānau struggle, especially those being violently aggressive in the home, to come out with that [ask for help] because of fear.

Hana's respond stance and response discourse shapes her responsiveness. She says it is the hauora that supports the family, by 'picking up the pieces'.

I can take care of the smaller things, like a mother may be feeling low self-esteem in herself again, because she's been told she's useless and she's a dumb bitch. That's where I can help, just by putting a little health plan together for her, regular exercise, looking at having a couple hours a day, or an hour a day by herself just to reflect. [...] Those are all the litthe things that we can do as a provider. So they don't think 'Oh is that it, I just have to have counselling'. There's other ways and means of making yourself feel a bit more important. Whether it be the mum or the father.

Hana's responsiveness derives from the strong relationship between her respond stance and response discourse. Her Triple R Pathway has self-organised to be as responsive as she can within the interactions she may influence, generating an adaptability to the changing environment. Her respond stance leaves room to co-evolve alongside whānau. For example, she will 'pick up the pieces' whatever they may be. Hana's wide understanding of the complexities involved in responding to IPV as a health issue for whānau initiates a responsive Triple $\mathrm{R}$ Pathway, however, she remains constrained by health and social systems which generate fear to ask for help.

\section{First Medical Care}

First Medical Care provides care to a general, mid-to-high socioeconomic patient population. We interviewed four First Medical Care workers: the practice manager, GP and two practice nurses. Across participants, we found the dominant respond stance, largely based on personal views, recognised IPV as an area not adequately addressed by First Medical Care. However, the dominant response discourse was IPV is not a problem for their patient population, that there is no 'clinical need'. A focus on top-down directives coupled with the absence of IPV recognition at the health system level reinforced this response discourse. It generated a paucity of knowledge on IPV as a key determinant of ill-health contributing to participant doubt of what to do. Competing response discourses were held by the practice nurses who were proactively responsive. Yet the dominance of the overall response discourse diminished their voices and generated system barriers which constrained their responsiveness. The following explores the Triple R Pathway of Mike, the practice manager of First Medical Care.

\section{Mike, practice manager}

Mike's response discourse 'we need an effective and consistent process' is informed by his position as practice manager, tasked with providing effective guidance for clinicians via protocols. Personally, Mike thinks of IPV as a human rights violation, his respond stance. He says, 'We're talking about freedom of choice here. Choose to smoke, I don't agree with their choice, but it's their choice. But when you're talking about how people are being abused, they're not choosing that'. Mike would be offended by people who do nothing because they don't know what to do. He believes New Zealand has an 'out of control domestic violence situation' and considers current responses to IPV as 'partial', 'not well connected, well-advertised, and probably not well enough used'.

It still relies on the person, who's just had their arm broken by their partner, or been raped by that person, they've still got to go home to that person, potentially, or sort themselves out with some other kind of help.

For Mike, consistency is the key to helping people, achieved through policy and protocol. He describes a procedure as the 'steering document' which guides clinician practice. Mike does acknowledge that a tension between clinical autonomy and prescriptiveness can challenge consistency and some variation will be involved, 'at what point you look to make a referral isn't so clear'. Nevertheless, it is his role to make the protocol as effective as possible 'because that's where they're going to turn to' when they encounter IPV.

Mike's respond stance and response discourse does not directly result in responsiveness. Although IPV is clearly an issue for Mike, there was no policy or protocol informing clinicians how to respond. He described the practice as focused on government targets and patient clinical needs. Therefore, he believed a government mandate would be needed to initiate a health system response because 'when there's no choice, we find a way, we always do'. The disconnection between Mike's response discourse and respond stance negatively impacts his responsiveness. Whether Mike recognises IPV as a clinical need or not, the influence of top-down directives, or lack of, will direct his practice.

\section{DISCUSSION}

Applying the Triple R Pathway to 17 health professional discourses on IPV as a health issue exposed two key areas where system interactions influence sustainable responses to IPV: (1) Non-recognition of IPV as a key determinant of ill-health. (2) Uncertainty and doubt. 


\section{IPV as a key determinant of ill-health}

We found an inadequate understanding of the relationship between healthcare and the socioecological contexts in which violence occurs, preventing an understanding of IPV as a key determinant of ill-health. This weak relationship allows the health system to restrict its response to addressing the health effects (such as injuries or depression), or simply identify and refer on to community services, without explicitly recognising IPV as a key determinant of ill-health. In practice, this means health professionals are less likely to see the cause behind the symptoms, missing opportunity to reduce risk and initiate change.

Variable recognition and understanding of socioecological determinants of violence existed at the clinical level, contributing to perceptions that there is no clinical need to address IPV, or that health professionals are already capable of and are addressing IPV effectively. Multiple, diverse and competing IPV response discourses each precluded potential interaction with other contexts which generated tensions in practice. For example, Hana the practice manager of Te Whānau Hauora, took offence to the assumption they would routinely enquire about IPV with patients as this did not reflect who they were as Māori. Understanding different IPV responses is particularly important for indigenous peoples whose voices are often unheard. ${ }^{28}$ We found exclusion of different response discourses at the health system level blocked transformation to more effective models of care for different populations, undermining health professional responsiveness.

The current inadequate understanding of the socioecological determinants of violence constrains primary care professional responsiveness to diverse contexts and populations, reinforcing inequities. Further, it diminishes the voices of those wanting to address IPV and limits learning. To prevent the health effects of violence and improve health and well-being, IPV must be effectively addressed. Recognising IPV as a key determinant of illhealth shifts the way a response may be conceptualised, calling attention to new and different ways to be responsive. As patterns of interaction across clinician, general practice and health system levels repeat to generate positive outcomes, sustainable responses to IPV will emerge. ${ }^{24}$

\section{Uncertainty and doubt}

We found the multiple competing IPV response discourses elicited by the Triple R Pathway generated uncertainty within the complex adaptive system. In practice, this uncertainty manifested as doubt of what to do. Doubt arose from the absent recognition of IPV within the health system (eg, not included within the health strategy, policy or protocols) and paucities of knowledge around IPV as a key determinant of ill-health, available response options and how to navigate health and social systems for referral. Primary care professionals also doubted what others may do in response to their action(s) for example, the patient response.
Despite the numerous IPV response discourses generating uncertainty and doubt, we argue prescribing a response is not a sustainable solution. We often try to reduce uncertainty through intentional means such as implementing a standardised intervention. Yet these measures have limited impact due to the unpredictability of complex adaptive systems. Our Triple R Pathway demonstrates how a response definition is continuously rearticulated based on who the person, or organisation, is and how they understand IPV. Instead, engaging with uncertainty supports the emergence of opportunities for change and improvement. We found primary care professionals who engaged with the inherent uncertainty of the future experienced less doubt. In the face of uncertainty, they asked more questions to decrease doubt. For example, a practice nurse held an 'instinct that something's not quite right' which, when triggered, motivated her to ask more questions. Those who engaged with uncertainty also understood their actions might trigger opportunities for change. For example, a practice nurse said

'...it's where will you be safe, where can you go to? And that's all I can do [...] because sometimes when you're in it you can't see past it, and sometimes what's needed is somebody on the outside saying "hey over here", you know "come over here" whether it be 5 minutes, ten minutes, or just a breather for them just to look outside of their own little box. It gives them an option; it gives them that little glimmer of hope that if they do take it, it might change.'

In contrast, those who avoided uncertainty were less responsive to care-seekers experiencing IPV. For example, a GP was reluctant to ask about IPV for fear of a positive disclosure and the possibility of an extended consult.

Our study shows uncertainty and doubt are not the same. Doubt is a lack of 'effective' responsiveness, such as not knowing what to do because of a lack of support. Uncertainty is an inherent part of being responsive, as knowing what to do does not eliminate the uncertainty of what may unfold. This challenges the common notion that variation is problematic for sustainability. ${ }^{29}{ }^{30}$ Our findings demonstrate engaging with diversity and uncertainty leads to improved responsiveness to those experiencing IPV. This also challenges the validity of pipeline intervention design and implementation. ${ }^{31}$ Rather, an intervention can be a very small change which generates new interactions within the complex adaptive system. The intervention may not always generate the desired effect, but when it does, the possibilities are amplified. Responses to uncertainty will always be uncertain. Engaging with uncertainty makes more sense than struggling against it by minimising or ignoring it. ${ }^{32}$

\section{Strengths, weaknesses and unanswered questions}

Use of complexity theory improves implementation science by calling attention to contextual factors and patterns of interaction influencing the implementation pathway. ${ }^{31}$ By calling attention to these two system areas 
which challenge sustainable responses to IPV, we offer opportunity to open discussion on how we might intervene to shift the health system in the desired direction. As we are yet to witness sustainable responses to IPV, we were unable to demonstrate how sustainability emerges. The largest weakness of this study is the absence of careseeker, community and whānau voices. Future research should explore the influence of these voices on healthcare responses to IPV. Use of complexity theory as a methodology must clearly justify research design choices, to provide a map of study boundaries which future research can build on and advance the use of complexity theory as a qualitative research methodology.

\section{CONCLUSIONS}

IPV is more than just a health issue, it is a key determinant of ill-health. Treating symptoms without addressing the cause is inadequate, ineffective and unsafe. The relationship between IPV and ill-health is not well recognised, or understood in New Zealand, at both policy and practice levels. Our Triple R Pathway emerged from exploring health professional discourses on IPV as a health issue and provided the means to understand what affects sustainable responses to IPV within New Zealand primary care settings. To improve responsiveness to IPV, the health system must widen its approach by adequately engaging with socioecological contexts to recognise IPV as a key determinant of ill-health. This will shift the way we conceptualise a response, calling attention to new and different ways to be responsive. Most importantly, we must become comfortable in engaging with uncertainty, at both policy and practice levels. A considerable body of knowledge already exists which we may call on to help probe into the unknown. The absence of primary care within a multisectoral response is a profound system gap which must be addressed if we are to prevent IPV in a sustainable way.

Acknowledgements The authors thank the health professionals who took time to share their stories and Ngāti Ranginui Kaumatua Tamati Tata, Dr Clare Healy and Dr Anna Rolleston for ongoing research advice and guidance.

Contributors CG designed and conducted the study under supervision by JK-M and EE. CG was the main manuscript writer. All authors read and approved the final manuscript. All authors accept responsibility for the conduct of the study, had full access to data and controlled the decision to publish. All authors accept responsibility for the integrity of the data and the accuracy of the data analysis.

Funding This work was supported by an Auckland University of Technology Vice Chancellor Doctoral Scholarship.

Disclaimer The funder had no role in study design, data collection, analysis or writing of the manuscript.

Competing interests CG received a Vice Chancellor Doctoral Scholarship from the Auckland University of Technology for the submitted work.

Patient consent for publication Not required.

Ethics approval Ethics approval for the study was granted by the Auckland University of Technology Ethics Committee (Ref 17/31).

Provenance and peer review Not commissioned; externally peer reviewed.

Data availability statement All data relevant to the study are included in the article or uploaded as supplementary information.
Open access This is an open access article distributed in accordance with the Creative Commons Attribution Non Commercial (CC BY-NC 4.0) license, which permits others to distribute, remix, adapt, build upon this work non-commercially, and license their derivative works on different terms, provided the original work is properly cited, appropriate credit is given, any changes made indicated, and the use is non-commercial. See: http://creativecommons.org/licenses/by-nc/4.0/.

\section{ORCID iDs}

Claire Gear http://orcid.org/0000-0002-1310-0188

Jane Koziol-Mclain http://orcid.org/0000-0003-3453-023X

Elizabeth Eppel http://orcid.org/0000-0001-5331-2911

\section{REFERENCES}

1 García-Moreno C, Hegarty K, d'Oliveira AFL, et al. The health-systems response to violence against women. Lancet 2015;385:1567-79.

2 Young-Wolff KC, Kotz K, McCaw B. Transforming the healthcare response to intimate partner violence: addressing 'wicked problems'. JAMA 2016;315:2517-8

3 World Health Organisation. Responding to intimate partner violence and sexual violence against women: WHO clinical and policy guidelines. Geneva: World Health Organization, 2013.

4 Taft AJ, Small R, Hegarty KL, et al. Mothers' AdvocateS In the Community (MOSAIC)-non-professional mentor support to reduce intimate partner violence and depression in mothers: a cluster randomised trial in primary care. BMC Public Health 2011;11:178.

5 Elvidge J. Strengthening the role of the GP in the treatment of family violence. Auckland, New Zealand: Public Health Promotion Unit, Auckland Healthcare, 1996.

6 Feder G, Davies RA, Baird K, et al. Identification and referral to improve safety (iris) of women experiencing domestic violence with a primary care training and support programme: a cluster randomised controlled trial. Lancet 2011;378:1788-95.

7 Ministry of Health. Overview of the health system, 2017. Available: https://www.health.govt.nz/new-zealand-health-system/overviewhealth-system [Accessed 14 Aug 2018].

8 Tenbensel T. Health System Regionalization - the New Zealand Experience. Healthc Pap 2016;16:27-33.

9 Waitangi Tribunal. Hauora. Wai 2575. Wellington, New Zealand: Waitangi Tribunal, 2019.

10 Fanslow J, Robinson E, Crengle S, et al. Juxtaposing beliefs and reality: prevalence rates of intimate partner violence and attitudes to violence and gender roles reported by New Zealand women. Violence Against Women 2010;16:812-31.

11 Dobbs T, Eruera M. Kaupapa Māori wellbeing framework: the basis for whānau violence prevention and intervention. Auckland, New Zealand: New Zealand Family Violence Clearinghouse, University of Auckland, 2014.

12 Family Violence Death Review Committee. Fourth annual report: January 2013 to December 2013. Wellington, New Zealand: Health Quality \& Safety Commission, 2014.

13 O'Campo P, Kirst M, Tsamis C, et al. Implementing successful intimate partner violence screening programs in healthcare settings: evidence generated from a realist-informed systematic review. Soc Sci Med 2011;72:855-66.

14 Gear C, Eppel E, Koziol-Mclain J. Exploring the complex pathway of the primary healthcare response to intimate partner violence in New Zealand. Health Res Policy Syst 2018;16.

15 Gear C, Koziol-McLain J, Wilson D, et al. Developing a response to family violence in primary healthcare: the New Zealand experience. BMC Fam Pract 2016;17:115.

16 McLean C, Koziol-McLain J, Howson M. Health response to family violence: 2017 violence intervention programme evaluation. Auckland, New Zealand: Centre for Interdisciplinary Trauma Research, Auckland University of Technology, 2018.

17 Gear C, Eppel E, Koziol-Mclain J. Utilizing complexity theory to explore sustainable responses to intimate partner violence in healthcare. Public Management Review 2018;20:1052-67.

18 McDaniel RR, Driebe DJ. Complexity science and healthcare management. In: Friedman L H, Goes J, Savage G T, eds. Advances in healthcare management. Emerald Group Publishing Limited, 2001: 11-36.

19 Begun JW, Kaissi AA. The social construction of uncertainity in healthcare delivery. In: McDaniel RR, Driebe DJ, eds. Uncertainity and surprise in complex systems: questions on working with the unexpected. Netherlands: Springer, 2010.

20 McDaniel RR, Driebe DJ, Lanham HJ. Healthcare organizations as complex systems: new perspectives on design and management. Adv HealthCare Manag 2013;15:3-26. 
21 Gear C, Eppel E, Koziol-Mclain J. Advancing complexity theory as a qualitative research methodology. Int J Qual 2018;17:160940691878255.

22 Cheek J. Postmodern and poststructural approaches to nursing research. Thousand Oaks, CA: Sage Publications, Inc, 2000.

23 Cilliers P. Complexity and postmodernism: understanding complex systems. London: Routledge, 1998.

24 Gear C. Sustaining primary care responses to intimate partner violence. Auckland: Auckland University of Technology, 2019. https:// openrepository.aut.ac.nz/handle/10292/12789

25 NUANCE. Dragon Professional Individual 15 [program].

26 QSR International. Nvivo 10 [Program] 2012.

27 De Fina A, Georgakopoulou A. Analyzing narrative: discourse and sociolinguistic perspectives. Cambridge, UK: Cambridge University Press, 2011.
28 Wilson D, Heaslip V, Jackson D. Improving equity and cultural responsiveness with marginalised communities: understanding competing worldviews. J Clin Nurs 2018;27:3810-9.

29 Colombini M, Dockerty C, Mayhew SH. Barriers and facilitators to integrating health service responses to intimate partner violence in low- and middle-income countries: a comparative health systems and service analysis. Stud Fam Plann 2017;48:179-200.

30 Goicolea I, Briones-Vozmediano E, Öhman A, et al. Mapping and exploring health systems' response to intimate partner violence in Spain. BMC Public Health 2013;13:1162.

31 Braithwaite J, Churruca K, Long JC, et al. When complexity science meets implementation science: a theoretical and empirical analysis of systems change. BMC Med 2018;16:63.

32 Khan S, Vandermorris A, Shepherd J, et al. Embracing uncertainty, managing complexity: applying complexity thinking principles to transformation efforts in healthcare systems. BMC Health Serv Res 2018;18:192. 